\title{
A new model for the fault beneath the sedimentary basin in the 1891 Nobi earthquake
}

\author{
Masaru Nakano ${ }^{1 *}$, Jun'ichi Miyakoshi $^{2}$, and Koshun Yamaoka ${ }^{3}$ \\ ${ }^{1}$ Graduate School of Environmental Studies, Nagoya University, Nagoya 464-8601, Japan \\ ${ }^{2}$ Shimizu Corporation, Tokyo 135-8530, Japan \\ ${ }^{3}$ Earthquake Research Institute, the University of Tokyo, Tokyo 113-0032, Japan
}

(Received December 17, 2004; Revised May 31, 2006; Accepted August 7, 2006; Online published March 15, 2007)

\begin{abstract}
We have investigated the geometry and detailed location of the Gifu-Ichinomiya (GI) fault, a buried fault considered to have ruptured during the 1891 Nobi earthquake. Based on an inversion of coseismic vertical displacements obtained by leveling surveys, we obtain an inclined fault plane showing a reverse fault-type mechanism, rather than the vertical fault plane assumed in previous models. The fault dips $60^{\circ}$ to the east and its slip during the earthquake is estimated to have been $1.48 \mathrm{~m}$ along the fault dip. The fault is located 5 $\mathrm{km}$ east of the location assumed in the previous models. Recent earthquakes have been scattered along the new fault location, not the previously estimated one. Focal mechanisms of the earthquakes that have occurred around the fault are dominated by a reverse fault component, which is consistent with the focal mechanism of the GI fault obtained by the inversion of coseismic displacements. The seismic intensity distribution calculated using the new fault geometry and location explains well the distribution of observed damage caused by the 1891 Nobi earthquake.
\end{abstract}

Key words: Gifu-Ichinomiya fault, Coseismic leveling survey, Earthquake distribution, Focal mechanism, Seismic damage estimation.

\section{Introduction}

The Nobi earthquake, which occurred on 28 October, 1891 ( $\mathrm{M}=8.0$, after Muramatsu, 1962), was one of the greatest inland earthquakes in Japanese history. This earthquake produced surface ruptures along the Nukumi, Neodani, and Umehara faults, extending NW-SE over $80 \mathrm{~km}$ (Fig. 1). These faults were dominated by a left-lateral strike-slip component with southwest side uplift (Matsuda, 1974). In addition to the ruptures of these faults, a rupture of the Gifu-Ichinomiya (hereafter GI) fault, located beneath the thick sediments of the Nobi plain, has been postulated on the basis of the distribution of damage caused by the Nobi earthquake (Muramatsu, 1963, 1983) and on careful investigation of coseismic displacements obtained from leveling surveys (Mikumo and Ando, 1976; hereafter abbreviated as MA76). The presence of the GI fault is also suggested by the vertical offsets of pumice beds observed in borehole records (Sugisaki and Shibata, 1961, 2003) and by gravity anomalies (Iida and Aoki, 1959).

The rupture model of the GI fault during the Nobi earthquake was intensively investigated by MA76. They assumed a vertical fault plane for the GI fault showing northeast side uplift, and subsequently attempted to explain the coseismic vertical displacements obtained by the leveling

\footnotetext{
*Now at National Research Institute for Earth Science and Disaster Prevention, Tsukuba 305-0006, Japan.

Copyright (c) The Society of Geomagnetism and Earth, Planetary and Space Sciences (SGEPSS); The Seismological Society of Japan; The Volcanological Society of Japan; The Geodetic Society of Japan; The Japanese Society for Planetary Sciences; TERRAPUB.
}

survey. Pollitz and Sacks (1994) proposed additional thrusts dipping northwestward to explain the triangulation and leveling data. Since these fault models were developed mainly by trial and error to obtain suitable fault parameters, an analysis based on data inversion is required.

The rupture of the faults associated with the Nobi earthquake greatly influenced the stress field around central Japan (e.g., Le Pichon et al., 1996). Recently, the effect of the Nobi earthquake on the occurrence date of the next Tokai earthquake, which is anticipated to occur in the near future and to cause great damage over a wide area in central Japan, has been discussed. Mogi (1981) proposed that the release of stress by the Nobi earthquake delayed rupture along the Suruga trough (the expected source region of the Tokai earthquake), which might otherwise have occurred during the 1944 Tonankai earthquake. Pollitz and Sacks (1995) and Rydelek and Sacks (2003) estimated the changes in the stress field around the Suruga trough due to the Nobi earthquake, using the fault model developed by Pollitz and Sacks (1994). They concluded that the Nobi earthquake had brought forward the rupture of the 1944 Tonankai and 1946 Nankaido earthquakes, while delaying the occurrence of the next Tokai earthquake until 2012. Reinvestigation of the Nobi earthquake fault model may, however, affect these estimates.

The existence of the GI fault is, on the other hand, still controversial. The local government (Aichi Prefecture, 1998, 2000) carried out seismic explorations using controlled sources across the estimated location of the GI fault in order to assess the potential activity of this fault in the 


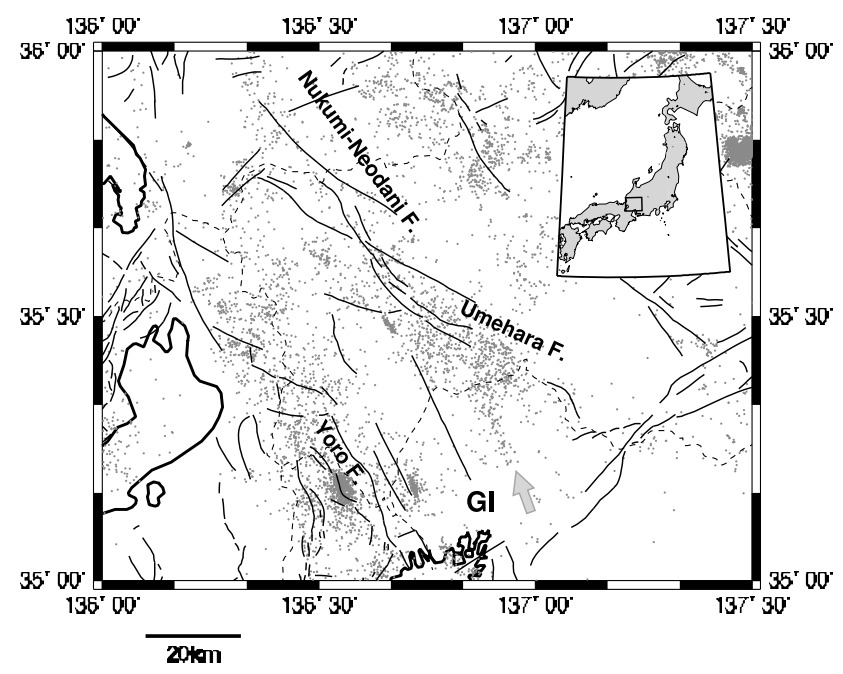

Fig. 1. Earthquake distributions (dots) in central Japan between 1983 and 2003, based on the data from Research Center for Seismology, Volcanology and Disaster Mitigation, Nagoya University. Solid lines indicate Quaternary active faults. The faults labeled "Nukumi-Neodani F." and "Umehara F." are well-known active faults that ruptured during the Nobi earthquake. Location of the Gifu-Ichinomiya fault (labeled "GI") is based on the previous models. There is a cluster of earthquakes about $10 \mathrm{~km}$ to the east of the GI fault (indicated by a gray arrow). The inset shows the location of the plotted area in Japan.

near future, and found no evidence of either fault or flexure. In response to that report, Sugisaki and Shibata (2003) reanalyzed borehole records around this region to search for the specific location of the GI fault. Their results indicate that the fault lies about $1.5 \mathrm{~km}$ to the east of the previous estimate of the fault location. They concluded that the local government survey had found no evidence of the fault because the survey was based on the old fault location. Since the previous estimate of the fault location was based only on its coincidence with the boundary between the regions of uplift and subsidence observed in the coseismic vertical displacements (Muramatsu, 1963, MA76), other possible locations of the fault need to be investigated. A detailed estimate of the fault location, as well as validated evidence of the fault itself, is critical for disaster mitigation planning in this region, because the fault runs in the basement rock beneath the thick sediments of the Nobi plain, where more than 4 million people live.

In this study, we carried out an inversion of coseismic displacements, obtained from leveling surveys across the GI fault, in order to obtain more detailed information on the geometry and location of the fault. We also used the distributions and focal mechanisms of recent earthquakes that occurred around the GI fault to obtain supplemental information about the fault geometry and location. Finally, we estimated the seismic intensity distribution based on the new fault model and compared it with observed damage caused by the Nobi earthquake.

\section{Geometry and Location of the Gifu-Ichinomiya Fault}

\subsection{Aftershock distribution}

Earthquake distribution around central Japan between 1983 and 2003 is shown in Fig. 1. Dense clusters of earth-

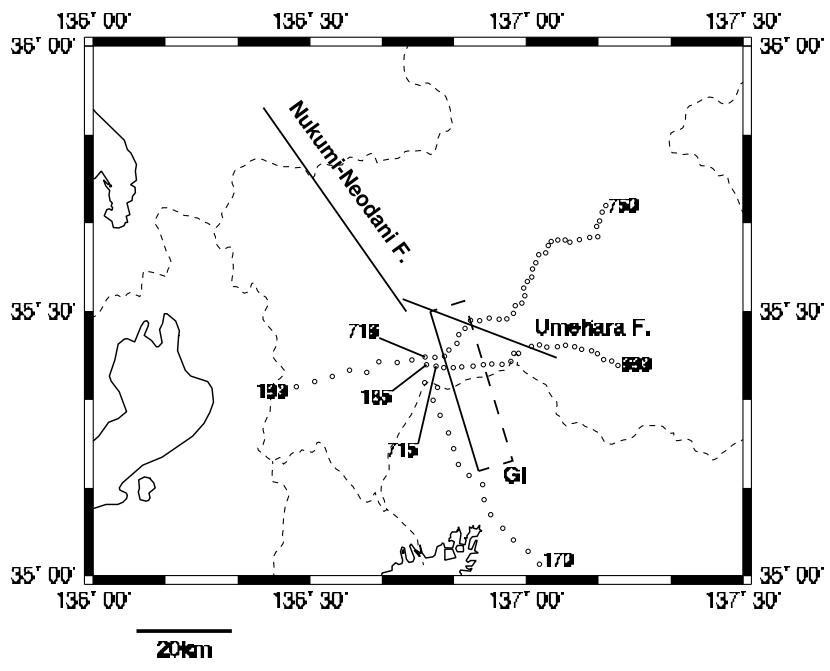

Fig. 2. The routes of the leveling surveys, along with fault locations used in the analysis. Open circles indicate benchmarks of the leveling surveys. The numbers correspond to specific benchmarks. The location of the GI fault shown in this figure is that of our final model. The solid and broken lines of the GI fault indicate the location of upper side and the other three sides of the inclined fault plane, respectively, projected onto the ground surface.

quakes are observed along the Nukumi-Neodani and Umehara faults; these earthquakes are considered to have been aftershocks of the Nobi earthquake, even though more than a century has passed since the main shock (Utsu et al., 1995). A linearly aligned cluster of earthquakes is also recognized about $10 \mathrm{~km}$ to the east of and parallel to the GI fault (Fig. 1). This earthquake cluster may also be considered to be aftershock activity of the Nobi earthquake if the GI fault ruptured during the earthquake, although the fault location needs to be reinvestigated.

The dip of the GI fault also needs to be reinvestigated. While a vertical fault plane was assumed in previous models (Muramatsu, 1963, 1983; MA76), most of the major faults in the Nobi plain are reverse faults that strike NW-SE. For example, the Yoro fault (Fig. 1), which is located in the southwestern Nobi plain, is characterized by a reverse fault striking NW-SE, with a gross vertical offset of more than 3 $\mathrm{km}$. The following subsections describe our search for the geometry and location of the GI fault consistent with the earthquake distribution, focal mechanisms of earthquakes in the clusters, coseismic displacements, and distribution of damage caused by the Nobi earthquake.

\subsection{Coseismic surface displacements}

Leveling surveys were conducted across the Umehara and GI faults between 1885 and 1890 , prior to the Nobi earthquake, and between 1894 and 1896, after the earthquake (Muto and Kawabata, 1934). Figure 2 shows the routes of the leveling surveys. Coseismic vertical displacements obtained from the leveling surveys are plotted on Fig. 3. We use the coseismic displacements to investigate the fault geometry and location of the GI fault. The reference benchmarks (BMs) of the leveling surveys were BMs 213, 715, and 716 for the routes between BMs 213-185, 715-693, and 716-750, respectively (Muto and Kawabata, 1934). Since BM 213 is located beyond the calculation area 
Table 1. Fault parameters of each fault segment of the 1891 Nobi earthquake.

\begin{tabular}{|c|c|c|c|c|c|c|c|}
\hline Segment & Strike $\left({ }^{\circ}\right)$ & $\operatorname{Dip}\left({ }^{\circ}\right)$ & Rake $\left(^{\circ}\right)$ & Slip (m) & Length $(\mathrm{km})$ & Width $(\mathrm{km})$ & Depth $(\mathrm{km})$ \\
\hline Nukumi & 145 & 90 & 45 & 1.4 & 18 & 15 & 0 \\
\hline Neodani (North) & 145 & 90 & 45 & 4.2 & 18 & 15 & 0 \\
\hline Neodani (South) & 145 & 90 & 0 & 7.0 & 16 & 15 & 0 \\
\hline Umehara & 111 & 90 & 53 & 1.20 & 35 & 15 & 0 \\
\hline Gifu-Ichinomiya & 163 & $60 \mathrm{E}$ & 90 & 1.48 & 35 & 15 & 1 \\
\hline
\end{tabular}
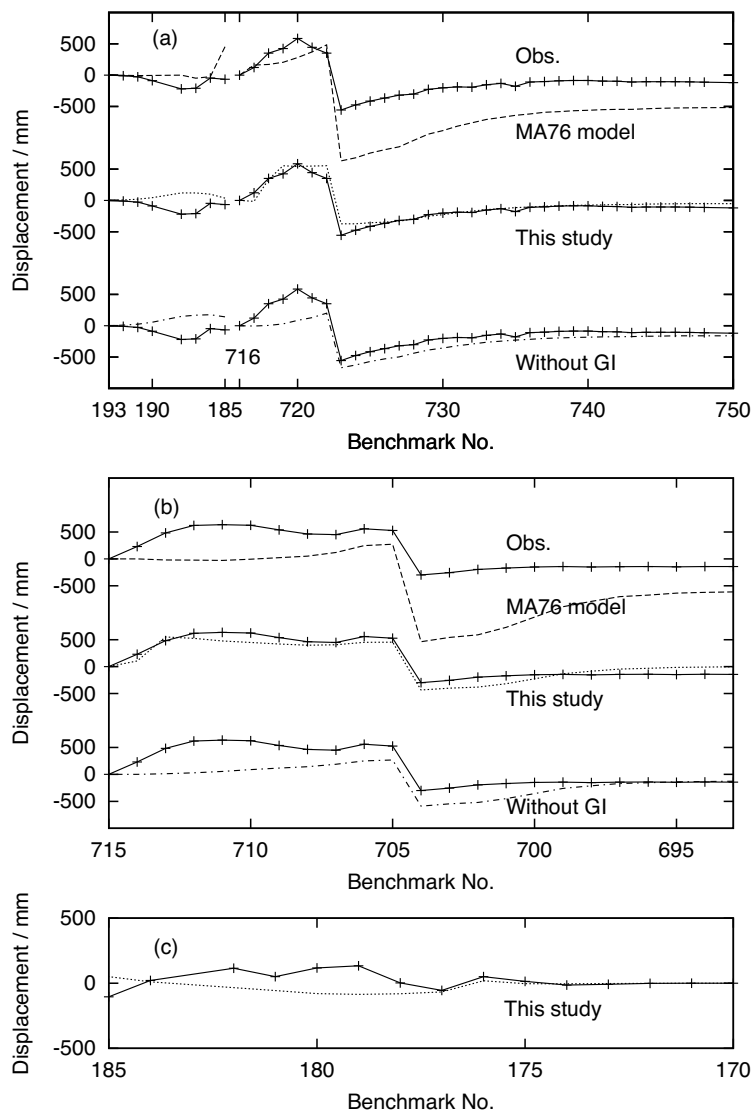

Fig. 3. Observed and calculated vertical displacements at every benchmark (BM) relative to the value at reference BMs. (a) The routes between BMs 193 and 185 and between BMs 716 and 750. (b) The route between BMs 715 and 693. (c) The route between BMs 185 and 170. Solid lines with crosses indicate observed displacements (labeled "Obs.") after Muto and Kawabata (1934). Broken lines indicate calculated displacements using the fault parameters of the GI fault based on Mikumo and Ando (1976) (labeled "MA76 model"), the parameters based on this study (labeled "This study"), and the case without the GI fault (labeled "Without GI"). The reference BMs of the routes are set to BM 193 (BMs 193-185), BM 716 (BMs 716-750), BM 715 (BMs 715-693), and BM 170 (BMs 185-170).

for the displacement field used in this study, we use the data between BMs 193 and 185 and set BM 193 as the reference. We do not use the leveling data of the route between BMs 170 and 184, which is parallel to the GI fault, since the displacements of this route may be strongly affected by inhomogeneous slip distribution on the fault.

The fault parameters we investigate include fault dip, depth, and slip (Table 1). Fault parameters such as strike, length, and width are assumed to be the same as those used in the MA76 model, which was based on Matsuda
(1974), since these parameters may not be well constrained by the leveling data used in this study. We assume a flat rectangular fault plane and uniform slip distribution on the fault. We consider only dip-slip components for the slip since strike-slip components may not be well constrained by the leveling data. All the faults are assumed to be 15 $\mathrm{km}$ wide. Accordingly, the lower bound of the GI fault depends on the assumed dip angle. We also investigate the E-W fault location because the fault location is also controversial, as described above (Sugisaki and Shibata, 2003). We include the slip amount of the Umehara fault in the free parameters, because the slip of $2 \mathrm{~m}$ assumed by MA76 for this fault gives much larger vertical displacement steps between BMs 722 and 723 and between BMs 705 and 704 than were observed (Fig. 3). Pollitz and Sacks (1994) assumed the slip of this fault to be $1 \mathrm{~m}$ for the same reason. We assume that the length of the Umehara fault was 35 $\mathrm{km}$, rather than the $25-\mathrm{km}$ value assumed by MA76 and Matsuda (1974), which was based on the observed surface rupture. The modified length of the Umehara fault gives nearly equal steps between BMs 722 and 723 and between BMs 705 and 704, which is consistent with the observed displacement (Fig. 3). The length of $25 \mathrm{~km}$ for this fault gives a much lower step between BMs 705 and 704 than that between BMs 722 and 723. The geometries and locations of the Neodani and Nukumi faults are assumed to be the same as those used in MA76 (Table 1) for the calculation of displacement fields.

The elastic displacements due to fault ruptures are calculated using MICAP-G (Naito and Yoshikawa, 1999), which uses the formulation of Okada (1992). The dip, depth, and fault location are determined by the grid search method. The dip is searched every $10^{\circ}$ in the range between $50^{\circ} \mathrm{E}$ and $90^{\circ} \mathrm{E}$. The upper limit and location of the fault are searched every $1 \mathrm{~km}$ between 0 and $9 \mathrm{~km}$ below sea level and 0 and $8 \mathrm{~km}$ eastward from that of the previous models, respectively. The parameters searched include those used in the model obtained by MA76. The slip amounts of the GI and Umehara faults are determined simultaneously by leastsquares inversion for each set of the grid-searched parameters. The model yielding the lowest residual of the inversion is adopted as our final model.

We obtained the following best-fit fault model. The GI fault dips $60^{\circ}$ to the east; its upper limit is $1 \mathrm{~km}$ below the ground surface; the fault is located $5 \mathrm{~km}$ to the east of the previous estimate (MA76; Table 1 and Fig. 2). The slip amounts along the fault planes are $1.48 \mathrm{~m}$ with eastern side uplift and $1.20 \mathrm{~m}$ with western side uplift for the GI and Umehara faults, respectively. The residual of the leastsquares inversion is 0.125 . The vertical displacements cal- 

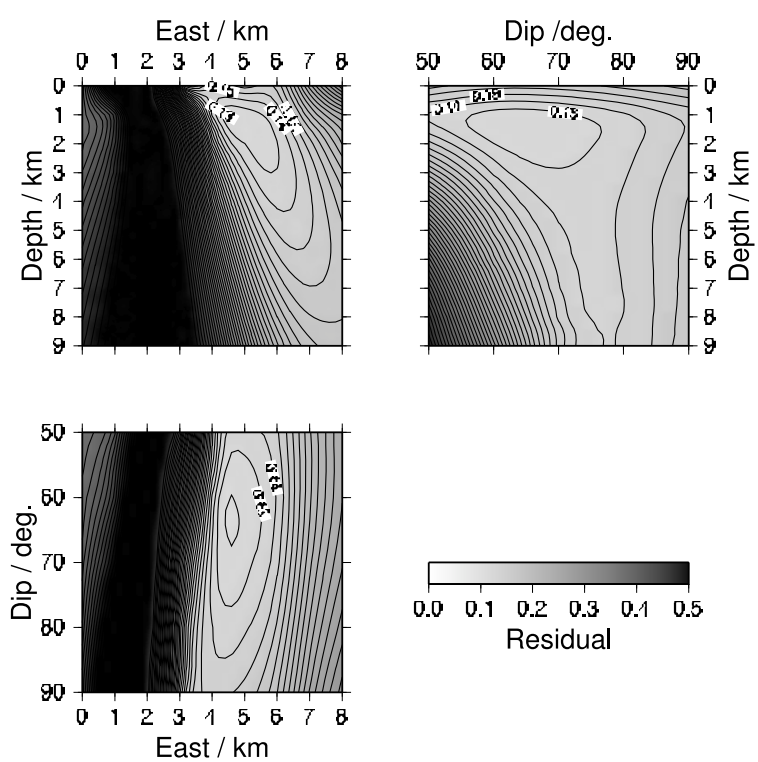

Fig. 4. Contour plots of residuals of inversions for grid-searched parameters. Cross-sections of three-dimensional parameter spaces that cut through the best-fit parameters are shown, namely $60^{\circ} \mathrm{E}$ for the dip, the upper limit of $1 \mathrm{~km}$ below the surface, and the fault location of $5 \mathrm{~km}$ to the east of the previously estimated location.

culated for the best-fit fault model along the leveling routes are shown in Fig. 3. Figure 3 also shows the displacements calculated for the MA76 fault model, in which we modified the length of the Umehara fault to $35 \mathrm{~km}$ simply because the modified fault length makes the steps between BMs 705 and 704 and between BMs 722 and 723 comparable, keeping the slip at its original value of $2 \mathrm{~m}$. The subsidence between BMs 190 and 185, which is one of the main features that MA76 tried to explain by introducing the GI fault, is not well reproduced by our model (Fig. 3(a)). However, our fault model explains the overall features of the displacements along the other leveling routes better than the MA76 model. Figure 4 presents contour plots of the residual distribution for each set of grid-searched parameters. It is clear that there are no local minima around the best-fit parameters, although there are some ambiguities in the fault dip and depth.

We also calculate displacements along the route between BMs 170 and 185 (Fig. 3(c)) using our fault model; we do not use the data of that route in the inversion. The discrepancies between BMs 185 and 177 may be due to lateral heterogeneity of slip distribution on the fault. Introducing inhomogeneous slip distributions to the GI fault may explain the displacement without affecting the leveling data used for the inversion.

\subsection{Focal mechanisms of earthquakes around the faults}

We next investigate the focal mechanisms of earthquakes that occurred around the GI and Umehara faults, including the cluster described in Section 2.1. The observation data used include the waveform records obtained by National Research Institute for Earth Science and Disaster Prevention (NIED), Research Center for Seismology, Volcanology and Disaster Mitigation, Nagoya University, Disaster Prevention Research Institute, Kyoto University, and

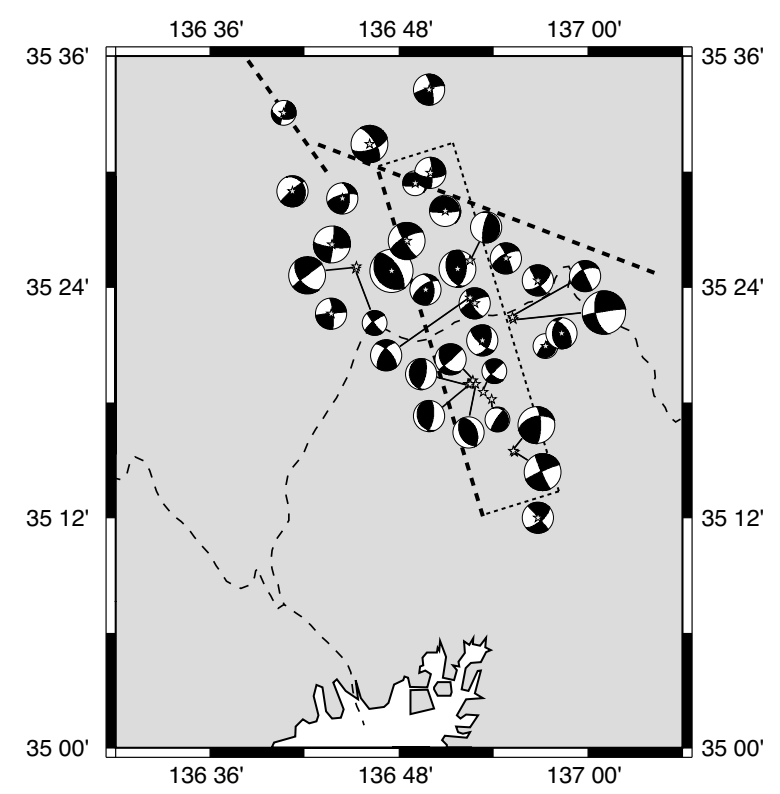

Fig. 5. Obtained focal mechanisms of earthquakes that occurred around the GI and Umehara faults. Stars indicate the epicenter locations and corresponding focal mechanisms are shown. The radius of each focal sphere is proportional to magnitude. Upper hemisphere projection is adopted. Broken lines indicate the faults associated with the Nobi earthquake. The bold and thin lines of the GI fault indicate the location of upper side and the other three sides of the inclined fault plane, respectively, projected onto the ground surface.

Metropolitan Seismic Observation Network of Tokai area (Tobita et al., 2001). The last observation network consists of seismic intensity sensors of local governments for felt earthquakes with the ability to record waveforms. Our analysis uses data for more than 30 earthquakes, with magnitudes between 1.5 and 3.6, that were observed between July 2001 and June 2004.

To determine focal mechanisms, we use maximum amplitudes of $P$-wave initial motion, including their polarity, and maximum envelope amplitudes of $S$-wave initial motion, measured by displacement seismograms at each station (Shimizu et al., 1987). The amplitudes of $P$-waves are weighted by a factor $\left(v_{p} / v_{s}\right)^{3}$ to compensate for geometrical decay, where $v_{p}$ and $v_{s}$ are $P$ - and $S$-wave velocities, respectively. We assume a homogeneous half-space for the crust, with $v_{p}=6.0 \mathrm{~km} / \mathrm{s}, v_{s}=3.65 \mathrm{~km} / \mathrm{s}$, and $\rho=2300$ $\mathrm{kg} / \mathrm{m}^{3}$, where $\rho$ is the density. Focal mechanisms are determined by the least-squares method with double-couple constraint. Both $P$ - and $S$-wave readings from at least ten stations surrounding the epicenter of each earthquake are used for the inversion. Resultant focal mechanisms inconsistent with the $P$-wave polarity distributions are omitted.

Figure 5 shows focal mechanisms obtained by the amplitude inversions. The compressional axes of most events are oriented nearly NW-SE, consistent with the regional stress field in this area. Around the GI fault, most earthquakes are of the reverse fault type. This result supports the reverse fault model of the GI fault obtained by the inversion of the coseismic displacements. Earthquakes with left-lateral strike-slip mechanisms, which are consistent with the geometry of the Umehara fault, are also observed. 
(a)

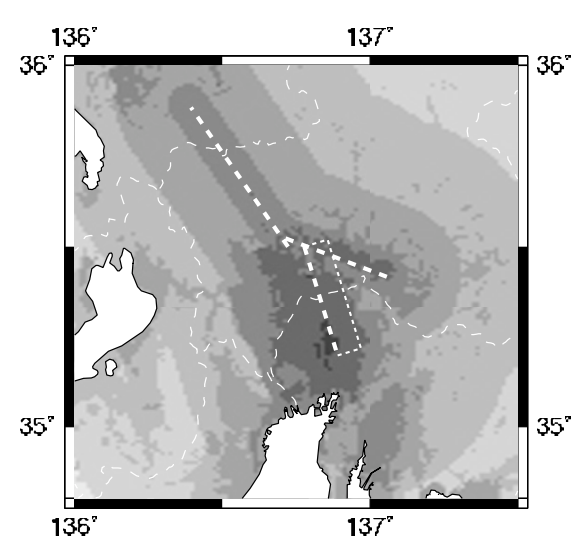

(b)

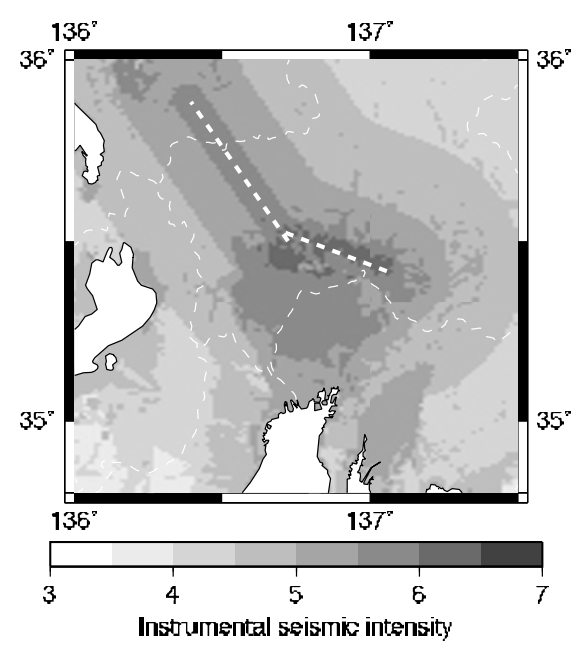

Fig. 6. Calculated seismic intensity distributions caused by the Nobi earthquake. (a) Based on our fault model. (b) Based on the model without the GI fault. Broken lines indicate the fault locations. The bold and thin lines of the GI fault are the same as Fig. 5.

\subsection{Seismic intensity distribution}

We investigate the seismic intensity distribution during the Nobi earthquake using empirical attenuation relations that are based on the GI fault model described in the previous sections. First, we estimate peak velocities at the top of the basement rock corresponding to $v_{s} \sim 600 \mathrm{~m} / \mathrm{s}$ using the method proposed by Si and Midorikawa (1999). This method estimates expected peak velocities at observation sites as a function of the gross magnitude due to all fault segments and the minimum distance from the faults. Second, we estimate the peak velocities on the ground surface from the peak velocities at the top of the basement rock, multiplied by amplification factors corresponding to surface soil structures. To evaluate the amplification factors, we use the method of Matsuoka and Midorikawa (1993). We refer to the digital national land information for the surface soil structures. Finally, we convert the peak velocities on the surface into the JMA instrumental seismic intensities using the method of Midorikawa et al. (1999). Note that the peak ground velocity used by the empirical relation of Midorikawa et al. (1999) is calculated from a vector addition of two horizontal components, while that calculated by the method of Si and Midorikawa (1999) is the larger of two horizontal components. The velocities differ between the two methods by at most a factor of 1.41 , which does not

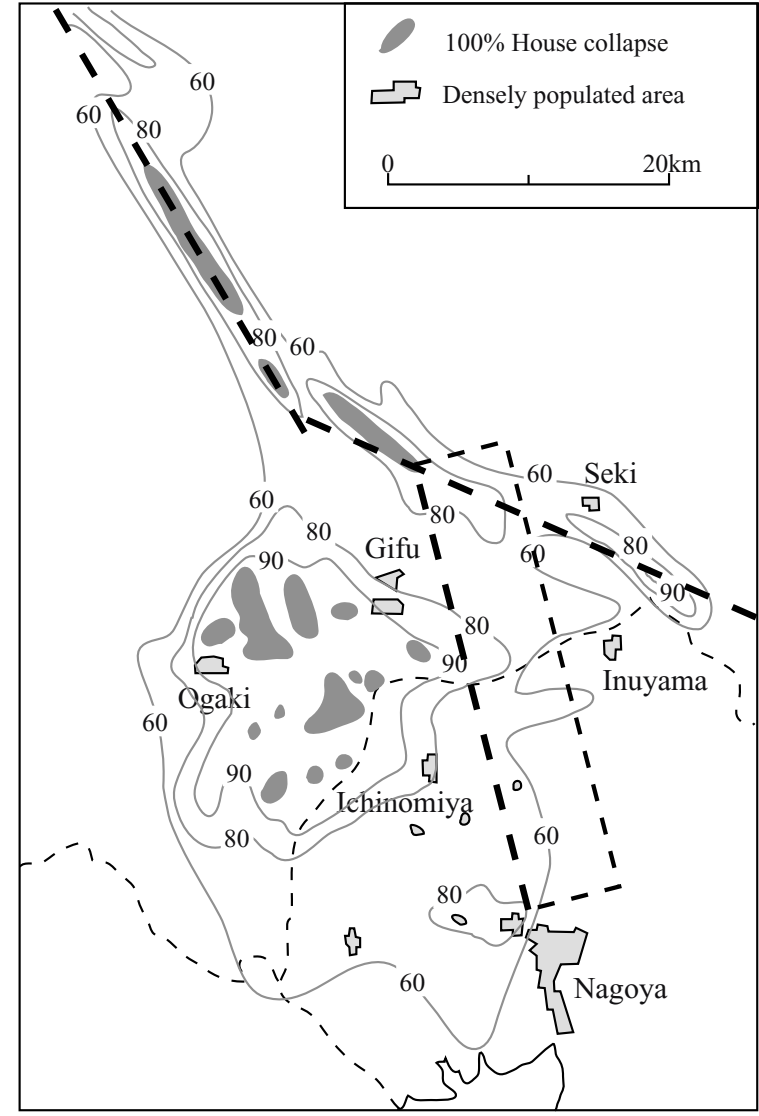

Fig. 7. Observed distribution of damage caused to wooden houses by the Nobi earthquake (modified from Muramatsu, 1983). Contour lines of the percentage of damaged houses are shown (see text for the definition of the values). Broken lines indicate the fault locations. The bold and thin lines of the GI fault are the same as Fig. 5.

affect our result, since we mainly focus on distributions in strongly damaged areas.

We use the following parameters to calculate the instrumental seismic intensity distribution: $M_{0}=1.38 \times 10^{20}$ $\mathrm{Nm}(\mathrm{Mw}=7.4)$ and $D=7.5 \mathrm{~km}$, where $M_{0}$ is the seismic moment due to all the fault segments and $D$ is the average center depth of the faults. The rigidity of the crust is assumed to be $30 \mathrm{GPa}$. We also estimate the seismic intensity distribution without the GI fault. This calculation yields $M_{0}=0.82 \times 10^{20} \mathrm{Nm}(\mathrm{Mw}=7.2)$ and $D=7.5 \mathrm{~km}$.

The calculated seismic intensity distributions are shown in Fig. 6. Figure 7 shows the distribution of damaged houses (in percentages) caused by the Nobi earthquake (modified after Muramatsu 1983), which was determined by $\left(N_{f}+0.5 \times N_{h}\right) / N_{t} \times 100$, where $N_{f}, N_{h}$, and $N_{t}$ were the number of collapsed houses, number of damaged houses, and total number of houses in each area, respectively. During the Nobi earthquake, severe damage was caused not only in the areas along the Nukumi-Neodani and Umehara faults but also in the southwest part of the Nobi plain (Muramatsu, 1963, 1983). Our model explains the severe damage observed in the southwest part of the Nobi plain (Fig. 6(a)) better than the model without the GI fault (Fig. 6(b)). We conclude that the severe damage observed in the southwest part of the Nobi plain was caused by the rupture of the GI fault. 


\section{Discussion}

Based on the comprehensive analyses of geodetic and seismological observations, we obtain an inclined fault plane showing a reverse fault type mechanism for the GI fault, rather than the vertical fault plane assumed by previous studies. The inversion of coseismic displacements indicates that the fault is a reverse fault dipping $60^{\circ}$ to the east, that its slip is $1.48 \mathrm{~m}$ along the fault dip with eastern side uplift, and that the upper limit of the fault was $1 \mathrm{~km}$ below the surface. The inversion also shows that the fault is located $5 \mathrm{~km}$ to the east of the previously estimated location. Recent earthquakes have been linearly distributed around the new fault location, not around the previously estimated location. Focal mechanisms of the earthquakes around the fault were of the reverse fault type, consistent with the geometry of the GI fault obtained by the inversion of coseismic displacements. The estimated seismic intensity distribution based on the new fault model is consistent with the seismic damage caused by the Nobi earthquake.

As described above, some studies have contested the existence of the GI fault (Aichi Prefecture, 1998, 2000; Matsuda, 1974). However, many investigations, including this study, support the existence and rupture of this fault during the Nobi earthquake (e.g. Muramatsu, 1963, MA76; Sugisaki and Shibata, 2003). As pointed out by Sugisaki and Shibata (2003), Aichi Prefecture's seismic reflection survey $(1998,2000)$ could not find the fault because it surveyed the previously estimated location. Matsuda (1974) proposed that the coseismic uplift observed around the southwest of the Umehara fault (around BMs 715-705 and 716-720) could be explained without the GI fault, because vertical displacements occur at the ends of finite-length strike-slip faults by their rupture (e.g., Chinnery, 1961). We calculated coseismic displacements without the GI fault (Fig. 3). The uplift indicated around BMs 715-705 and 716-720 could not be reproduced without the GI fault. Therefore, we conclude that the GI fault exists and that it ruptured during the Nobi earthquake.

The coseismic displacements used in this study were obtained in 1894-1896, a few years after the Nobi earthquake. Therefore, the leveling data may include postseismic displacements as well as coseismic displacements. In fact, displacements with a magnitude of a few millimeters were observed by repeated leveling surveys after the earthquake, although they were difficult to distinguish from observational errors (Muto and Kawabata, 1934). Therefore, the amount of the fault slip obtained in this study may include the effects of postseismic displacements.

In the inversion of the coseismic displacements, we assume simple fault geometry as a flat rectangle with a uniform slip. Because actual faults may have more complex shapes, rough surfaces, or inhomogeneous slip distributions, these assumptions limit the resolution of detailed fault geometries. The crossing of the GI fault and the Umehara fault demonstrated in our results may be an artifact of these simplifications. The discrepancy between the observed and calculated vertical displacements of the route between BMs 170 and 185 (Fig. 3(c)), which are not used in the inversion, also may be due to these limitations. The location of the upper side of the GI fault obtained in this study is a few

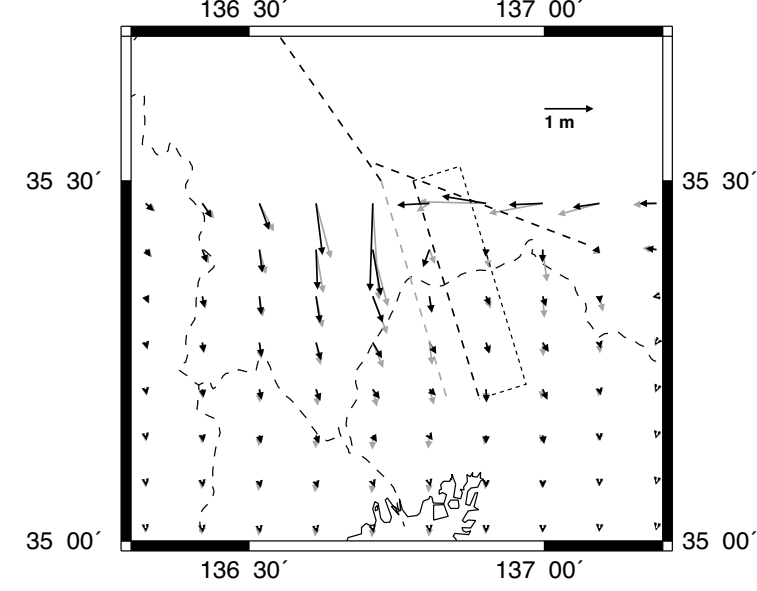

Fig. 8. Calculated horizontal displacements around the GI fault during the Nobi earthquake. Black arrows indicate the results based on our fault model. Gray arrows indicate the results based on the MA76 fault model. Black broken lines show the locations of Nukumi-Neodani, Umehara, and GI faults. The bold and thin lines of the GI fault are the same as Fig. 5. Gray broken lines show the location of the GI fault used in the calculation based on the MA76 fault model.

kilometers to the east of that estimated by Sugisaki and Shibata (2003). Their study also showed that vertical offsets of Quaternary pumice beds (80-90 thousand years old) due to ruptures of the GI fault have been observed to be as shallow as a few tens of meters below the surface, much shallower than our results. These discrepancies in the detailed fault location may also be due to the simplifications of the fault geometry. Introducing complex fault geometry, which is beyond the scope of the present study, may resolve these discrepancies. The use of complex fault geometry may affect the estimate of fault parameters and seismic intensity distributions to some degree. The findings of the present study in terms of the reverse fault type mechanism and the new location of the GI fault east of the previously estimated location, however, will not alter.

We compare horizontal displacements around the northern end of the GI fault calculated by our fault model of the Nobi earthquake and the model obtained by MA76 (Fig. 8). In the calculation of the horizontal displacements for the MA76 fault model, we use the modified fault length of the Umehara fault described above. This modification results in a slightly different displacement field from that shown by MA76 (Fig. 6 in MA76). The observed horizontal displacements obtained from the geodetic triangulation measurements show southeastward displacements around the northern end of the GI fault (Sato, 1974). Our fault model replicate this observation less than the MA76 fault model, possibly because our model considers only dip-slip components for the fault slip. Further investigation, which is beyond the scope of our present work, may be required, including a study of the effects of detailed fault geometries, or inversions including horizontal displacements.

The reverse fault mechanism of the GI fault obtained in this study is similar to fault geometries of the other faults in the Nobi plain, such as the Yoro fault (Fig. 1), one of the major thrust faults in the Nobi plain. In contrast, left-lateral strike-slip fault mechanisms, such as the Nukumi-Neodani 
faults, predominate in the north of the Nobi plain. The GI and Umehara faults may provide the transition boundary of the fault mechanisms. Although the simultaneous faulting of the Umehara and GI faults during the Nobi earthquake seems peculiar, their faulting may be controlled by the complex stress field around this area.

The vertical displacements of the Quaternary pumice beds average $5.6 \mathrm{~m}$, and larger displacements are observed in deeper gravel beds (Sugisaki and Shibata, 2003), while the vertical offset of the GI fault obtained by this study is only $1.48 \mathrm{~m}$ along the fault dip during the Nobi earthquake. Therefore, the GI fault may have been activated repeatedly at average intervals of about 20-30 thousand years, with assumed amounts of displacement at each faulting similar to those of the Nobi earthquake. The recurrence intervals of the other segments are about 2300-2400, 2700, and 10,000 years for the Nukumi, Neodani, and Umehara faults, respectively (Okada et al., 1992; Yoshioka and Awata, 2001). Therefore, the activity of the GI fault is expected to be much less than the other segments. The 1891 Nobi earthquake may have been extraordinarily large, and the penultimate faulting event of each segment occurred in a different era (Okada et al., 1992). The next activation of the GI fault may occur after a few tens of thousands of years.

\section{Conclusion}

We investigated the fault geometry of the GI fault during the 1891 Nobi earthquake. On the basis of an inversion of coseismic displacements obtained from leveling surveys, we obtained an inclined fault plane showing a reverse fault type mechanism for the GI fault, rather than the previously assumed vertical fault. The fault is located $5 \mathrm{~km}$ east of the previously estimated location. Recent earthquakes have been scattered around the new location. The focal mechanisms of these earthquakes are dominated by a reverse fault component, consistent with the result of the inversion of the coseismic displacements. Seismic intensity distribution estimated from our fault model explains well the distribution of damage caused by the Nobi earthquake.

Acknowledgments. We are grateful to Dr. Y. Hayashi and Dr. T. Sagiya for providing valuable discussions and suggestions. Most of the figures were drawn by using GMT (Wessel and Smith, 1991).

\section{References}

Aichi Prefecture, Report of the survey about the Gifu-Ichinomiya and Yoro-Kuwana-Yokkaichi faults, in Report of the survey of active faults in 1997, edited by Aichi Prefecture, 118 pp., Aichi Prefecture, 1998 (in Japanese).

Aichi Prefecture, Report of the exploration of underground structure in Nobi Plain, in Report of the survey of underground structure in 2000, edited by Aichi Prefecture, 42 pp., Aichi Prefecture, 2000 (in Japanese).

Chinnery, M. A., The deformation of ground around surface faults, Bull. Seismol. Soc. Am., 51, 355-372, 1961.

Iida, K. and H. Aoki, Gravity anomalies and subterranean mass distribution, with special reference to the Nobi plain, Japan, J. Geod. Soc. Japan, 5, 88-91, 1959 (in Japanese with English abstract).

Le Pichon, X., F. Pollitz, M. Fournier, J. P. Cadet, S. Lallemant, and N. Chamot-Rooke, Distribution of shortening landward and oceanward of the eastern Nankai trough due to the Izu-Ogasawara ridge collision, Earth Planet. Sci. Lett., 137, 145-156, 1996.

Matsuda, T., Surface faults associated with Nobi (Mino-Owari) earthquake of 1891, Japan, Spec. Rep. Earthq. Res. Inst., 13, 85-126, 1974 (in Japanese with English abstract).
Matsuoka, M. and S. Midorikawa, Prediction of isoseismal map for large area using the digital national land information, J. Struct. Constr. Eng., $A I J, 447,51-56,1993$ (in Japanese with English abstract).

Midorikawa, S., K. Fujimoto, and I. Muramatsu, Correlation of new J.M.A instrumental seismic intensity with former J.M.A. seismic intensity and ground motion parameters, J. Social Safety Sci., 1, 51-56, 1999 (in Japanese with English abstract).

Mikumo, T. and M. Ando, A search into the faulting mechanism of the 1891 great Nobi earthquake, J. Phys. Earth, 24, 63-87, 1976.

Mogi, K., Seismicity in western Japan and long-term earthquake forecasting, Earthquake Prediction: An International Review, Maurice Ewing Series 4, edited by D. W. Simpson and P. G. Richards, pp. 43-51, American Geophysical Union, Washington, 1981.

Muramatsu, I., Magnitude of the Nobi earthquake, Oct. 28, 1891, Zisin, 15, 341-342, 1962 (in Japanese).

Muramatsu, I., Distribution of seismic intensity and crustal deformation in the region destroyed by the great Nobi earthquake of October 28, 1891, Res. Rep., Gifu Univ., 3, 202-224, 1963 (in Japanese with English abstract).

Muramatsu, I., Distribution of the percentage of collapsed houses in the Nobi Plain for the Nobi earthquake of 1891, Res. Rep., Gifu Univ., 7, 867-882, 1983 (in Japanese with English abstract).

Muto, K. and Y. Kawabata, Vertical displacements of bench marks in the Nobi and other districts, Bull. Earthq. Res. Inst., 11, 315-328, 1934 (in Japanese with English abstract).

Naito, H. and S. Yoshikawa, A program to assist crustal deformation analysis, Zisin, 52, 101-103, 1999 (in Japanese).

Okada, A., M. Watanabe, M. Ando, T. Tsukuda, and S. Hirano, Estimation of paleo-seismicity in the Nobi active fault system, central JapanExcavation study of the Umehara fault, central strand in the Nobi active fault system, J. Geogr., 101, 1-18, 1992 (in Japanese with English abstract).

Okada, Y., Internal deformation due to shear and tensile faults in a halfspace, Bull. Seismol. Soc. Am., 82, 1018-1040, 1992.

Pollitz, F. F. and I. S. Sacks, Fault model of the 1891 Nobi earthquake from historic triangulation and leveling, J. Phys. Earth, 42, 1-43, 1994.

Pollitz, F. F and I. S. Sacks, Consequences of stress changes following the 1891 Nobi earthquake, Japan, Bull. Seismol. Soc. Am., 85, 796-807, 1995.

Rydelek, P. A. and I. S. Sacks, Triggering and inhibition of great Japanese earthquakes: the effect of Nobi 1891 on Tonankai 1944, Nankaido 1946, and Tokai, Earth Planet. Sci. Lett., 206, 289-296, 2003.

Sato, H., A study of horizontal movement of the earth crust associated with destructive earthquakes in Japan, Bull. Geogr. Survey Inst., 19, 89-130, 1974

Shimizu, H., S. Ueki, and J. Koyama, A tensile-shear crack model for the mechanism of volcanic earthquakes, Tectonophysics, 144, 287-300, 1987.

$\mathrm{Si}, \mathrm{H}$. and S. Midorikawa, New attenuation relationships for peak ground acceleration and velocity considering effects of fault type and site condition, J. Struct. Constr. Eng., AIJ, 523, 63-70, 1999 (in Japanese with English abstract).

Sugisaki, R. and K. Shibata, Geochemical study on ground water (I)Subsurface geology and aquifers in the Nobi plain, J. Geol., 67, 335345, 1961 (in Japanese with English abstract).

Sugisaki, R. and K. Shibata, Reappraisal of the Gifu-Ichinomiya FaultPoints at issue for recognition of concealed fault under an alluvial plain, Zisin, 56, 281-296, 2003 (in Japanese with English abstract).

Tobita, J., N. Fukuwa, M. Nakano, and K. Yamaoka, Development of online data acquisition system for strong motion seismic records and its application to existing observation sites, AIJ J. Technol. Des., 13, 4952, 2001 (in Japanese with English abstract).

Utsu, T., Y. Ogata, and R. S. Matsu'ura, The centenary of the Omori formula for a decay law of aftershock activity, J. Phys. Earth, 43, 133, 1995.

Wessel, P. and W. H. F. Smith, Free software helps map and display data, EOS Trans. Am. Geophys. U., 72, 445-446, 1991.

Yoshioka, T. and Y. Awata, Behavioral segmentation of the surface ruptures associated with the 1891 Nobi earthquake, central Japan, based on paleoseismological studies, EOS Trans. Am. Geophys. U. Fall Meeting 2001 abstracts, paper No. S52D-0662, 2001.

M. Nakano (e-mail: mnakano@bosai.go.jp), J. Miyakoshi, and K. Yamaoka 